\title{
Experiences of unmet need and access to supportive care for men receiving androgen deprivation therapy for prostate cancer: a bi- national study.
}

PATERSON, C., PRIMEAU, C., HOWARD, N., XIBERRAS, P., PILLAY, B. and CROWE, $\mathrm{H}$. 
Experiences of unmet need and access to supportive care for men receiving androgen deprivation treatment for prostate cancer: A bi-national study

Catherine Paterson, PhD, MSc, BA, PgCert LTA, FHEA, PG Non-medical prescriber, RAN; Charlotte Primeau, BSc, MSc, PhD; Nicholas Howard, PhD; Peter Xiberras, PhD; Brindha Pillay, PhD; Helen Crowe, MSc, RN

Author Affiliations: University of Canberra, ACT (Dr Paterson) Robert Gordon University, Aberdeen, Garthdee, Scotland (Drs Paterson and Primeau); Epworth HealthCare, Victoria, Australia (Drs Howards, Xiberra, Pillay and Mrs Crowe); Peter MacCallum Cancer Centre, Victoria Australia (Dr Pillau and Mrs Crowe); and Royal Melbourne Hospital, Victoria Australia (Dr Pillau and Mrs Crowe)

\section{Correspondence:}

Dr Catherine Paterson

Clinical Chair in Nursing

Faculty of Health

School of Nursing, Midwifery \& Public Health

University of Canberra ACT 2601

\&

Canberra Health Services

SYNERGY Nursing \& Midwifery Research Centre | ACT Health Directorate

Level 3, Building 6, Canberra Hospital | GPO Box 825 Canberra ACT

Email: Catherine.paterson@canberra.edu.au

Acknowledgements: We would like to thank all the men who took part in this study.

Conflicts of Interest: The authors have no funding or conflicts of interest to disclose.

Part of this work was presented at $19^{\text {th }}$ Asia-Pacific Prostate Cancer Conference (APCC). Australia. 


\section{Abstract}

Objective: Men affected by incurable prostate cancer is expected to increase worldwide. Research is needed to enable men to share their experiences of unmet supportive care needs in current care delivery. We aimed to identify the most frequently reported domains of unmet supportive care needs, levels of anxiety, depression, distress, health-related quality of life, and to identify any perceived barriers to receiving supportive care.

Data Sources: Men diagnosed with prostate cancer who had received a minimum of 6 months of ADT were recruited into a cross-sectional study. Participants completed standardised questionnaires, clinical and demographic data was also collected.

Conclusion: 272 patients were invited, and 102 participated. No statistically significant differences were found between participants scores from Australia and UK in relation to anxiety and depression, exercise, HRQoL or distress scores. Perceived barriers in service delivery related to information provision and difficulties in the navigation of complex care systems.

Implications for Nursing Practice: Men affected by prostate cancer receiving ADT reported unmet supportive care needs, specifically related to sexual, informational and psychological aspects of care. Mapping future trajectories of needs and identifying men at high risk can significantly improve timely and tailored interventions.

Key words: access to services; androgen deprivation therapy; locally advanced; metastatic; patient care; prostate cancer; supportive care; unmet needs. 


\section{Introduction}

Prostate cancer remains the most common cancer among older men, and is the second leading malignancy in the western world ${ }^{1}$. The mainstay treatment for advanced prostate cancer disease aims to reduce systemic testosterone levels, which can be achieved surgically or by chemical castration, known as androgen deprivation therapy (ADT) ${ }^{2}$. However, newer therapies for advanced prostate cancer have improved survival rates ${ }^{3-7}$ and therefore, many more men are requiring on-going supportive care.

Men affected by advanced prostate cancer have an incurable disease, and men can report a range of unmet supportive care needs in routine service delivery ${ }^{8-10}$. Moreover, men can experience a range of symptoms that can negatively affect their quality of life and can increase the need for supportive care interventions ${ }^{11,12}$. Side effects which have been identified as particularly challenging include: (i) body feminization (gynecomastia, hot flushes, loss of muscle mass, genital shrinkage); (ii) changes in sexual function and lack of libido; (iii) relationship changes; (iv) cognitive and affective symptoms; and (v) fatigue, sleep disturbance, and depression $8,13,14$.

Supportive care is a person-centred approach to the provision of the necessary services for those living with or affected by prostate cancer to meet their informational, spiritual, emotional, social, or physical needs during diagnosis, treatment, or follow-up phases including issues of health promotion and prevention, survivorship, palliation and bereavement ${ }^{15}$. The need to improve supportive and palliative care for adults with incurable cancer is recognised internationally ${ }^{16}$ to increase patient satisfaction with demonstrated cost-effectiveness. Additional research is needed to enable men to share their experiences to understand why unmet supportive care needs are persistent in current care delivery 15,17. This study aims to investigate the unmet supportive care needs experienced by men affected by advanced prostate cancer in two countries with similar healthcare systems. Gaining more evidence in this area will contribute towards a better understanding of unmet needs to inform recommendations 
for models of advanced prostate cancer care. Therefore, this study aimed to address the following research questions:

1) What are the most frequently reported domains of unmet supportive care needs by men affected by advanced prostate cancer receiving $A D T$, and are they different between countries?

2) What are the self-reported levels of anxiety, depression, health-related quality of life and distress experienced by men affected by advanced prostate cancer receiving ADT?

3) What are men's experiences of the barriers to receiving appropriate supportive care?

\section{Methods}

Design

An observational, cross-sectional quantitative design was conducted.

\section{Conceptual framework}

The conceptual framework for this study was informed by the prostate cancer model of consultation 18 to identify the standardised questionnaire instruments to be used in this study to address the research questions.

\section{Setting}

After ethical approval was granted (UK: 16/WS/0211 and Australia: 16/MH/12) this study recruited patients from the UK and Australia. Patients were recruited in United Kingdom, National Health Service (NHS) Tayside which serves a predominantly Caucasian rural and urban population of more than 405,721 and is served by 75 general practices and single tertiary urological cancers services. Patients were recruited in Victoria, Australia from a range of private practices associated with Epworth Healthcare Richmond and the public men's health clinic at the Australian Prostate Centre. These locations offered a good cross-section of this patient population with both public and privately insured patients being included. Moreover, this study specifically explored the experiences of unmet needs of 
men affected by advanced prostate cancer in Australia and the UK because both countries are developed and have access to a publicly funded healthcare system.

\section{Participants}

Inclusion: Patients were recruited into the study if they met the following inclusion criteria:

a) diagnosed with locally advanced or metastatic prostate cancer who are currently undergoing treatment with ADT,

b) commenced ADT at least 6 months prior to study enrolment,

c) able to read and write English or agreeable to access translation support and,

d) provided informed consent by returning the questionnaire pack where consent had been explained in the accompanying letter.

\section{Exclusion criteria}

a) patients undergoing concomitant or previous radiotherapy or chemotherapy for their prostate cancer.

\section{Recruitment}

All eligible patients were identified by clinicians at the study sites. Members of the healthcare team were responsible for sending a letter of invitation and recruitment packs. The recruitment packs contained the following: participant information sheet, questionnaire pack and a stamped, selfaddressed return envelope. No further follow-up contact was made with patients who did not return their questionnaires. Informed consent was implied on the bases of a completed questionnaire.

\section{Variables}

Clinical and demographic data was collected from the questionnaires. The information collected included the following:

- Demographic variables: age, marital status, sexual orientation, ethnicity, level of education, health insurance status, and employment status. 
- Clinical variables: time since diagnosis, date of commencement of ADT, and whether ADT was intermittent or continuous therapy.

\section{Patient reported outcome measures}

Supportive Care Needs Survey (SCNS-SF34) and the prostate-specific module

The Supportive Care Needs Survey is a validated instrument assessing perceived need in the domains of psychological needs, health system and information needs, physical and daily living needs, patient care and support, sexuality, need for access to services and resources ${ }^{19}$. A short form (34 items) of this survey (SCNS-SF34) has been validated for use in men with prostate cancer ${ }^{20}$.

Expanded Prostate Cancer Index Composite short form (EPIC-26)

The EPIC-26 is a self-report 26-item to measure of health-related quality of life among prostate cancer patients ${ }^{21}$, that has been shown to have good reliability and validity. EPIC items have Likert scale response options with higher scores representing better quality of life.

\section{Godin Leisure-Time Exercise Questionnaire}

The Godin Leisure-Time Exercise Questionnaire ${ }^{22}$ is a 4-item self-report measure of physical activity engagement. It has been shown to have good reliability and validity in measuring engagement in physical activity.

The Distress Thermometer (DT)

The DT is a widely used 1-item visual analogue scale which measures self-reported distress. This measure has been validated for use with men with prostate cancer ${ }^{23}$. A score of 4 or above indicates clinically elevated levels of distress. 
General Anxiety Disorder-7 (GAD-7)

The GAD-7 was used to assess anxiety ${ }^{24}$. The GAD-7 was developed from the DSM-IV-TR (Diagnostic and Statistical Manual of Mental Disorders, fourth edition, Text Revision) ${ }^{25}$ diagnostic criteria for Generalised Anxiety Disorder. The GAD-7 has widely demonstrated reliability and validity in general and primary care patient populations ${ }^{26}$. It has also been recommended for use in screening and assessment in adult cancer patient populations ${ }^{27}$.

Patient Health Questionnaire (PHQ-9)

The PHQ-9 ${ }^{28}$ was developed from the diagnostic criteria for Major Depressive Disorder (MDD) from the DSM-IV-TR ${ }^{25}$. This measure was used to assess depression. The PHQ-9 has been shown to possess good validity for patients with mild, moderate and severe depression.

\section{Supportive Care Services Survey}

Patients were asked to identify the medical and allied health practitioners involved in their care and any supportive services they accessed since they commenced ADT. They were asked to identify any supportive care services they would like to have access to, but have been unable to do so, and to select reasons why they have not been able to access these. Barriers to supportive care services that were listed in the questionnaire was informed ${ }^{29}$.

\section{Statistical methods}

Prior to the analysis, variables were examined for accuracy of data entry, missing values and the assumptions of the proposed analysis. This verification was done through traditional exploratory analysis ${ }^{30}$. Normality distributions of the variables were checked by statistical and graphical methods. Skewness and Kurtosis significance values were assessed using the Kolmogorov-Smirnov (K-S) test and a histogram was plotted for each variable. To address the research questions, statistical analysis was performed using descriptive statistics and non-parametric tests (chi ${ }^{2}$ test and Mann-Whitney U). 


\section{Results}

A total of 105 patients from United Kingdom and a total of 167 patients from Australia were invited to participate. A total of 102 ( $n=41$ UK, $n=61$ Australia) men diagnosed with locally advanced or metastatic prostate cancer consented to take part in the study (37.5\% response rate). The reasons for non-participation in this study will remain unknown due to the cross-sectional postal survey design and ethical restrictions placed on collecting clinical and demographic data of the non-participants. Most of the study participants were $>70$ years of age $(80.4 \%)$, married $(76.5 \%)$, retired $(77.5 \%)$, and Caucasian (86.3\%), see Table 1 for clinical and demographic characteristics of the study participants.

We observed a statistically significant difference in age between the study participants in UK median $80.9(66-91)$ years, and Australia $76.4(61-96)$ years, $p=.034$ respectively. Statistically significant differences were also observed in time since diagnosis between the UK (median 3 [1-11] years) and Australia (10 [2-30] years), $p=.000$, and the duration of ADT between the countries UK (1.6 [0-9] years) and Australia (3.2 [0-19] years), $p=.004$.

Men experienced a range of unmet supportive care needs with the highest scores relating to informational, psychological and sexual needs, see Table 2. No statistically significant differences in unmet needs between the participants from UK or Australia were observed in relation to the physical and daily, patient care and support, sexuality, psychological or informational needs, see Table 3. Moreover, no statistically significant differences were found between scores from Australia and UK in relation to anxiety and depression scores, exercise scores, and HRQoL domains. The only exception was on the matter of urinary incontinence, see Table 3.

Using the PHQ-9 cut-off scores of 0-4 (no depression), 5-9 (mild), 10-14 (moderate) 15-19 (moderately severe) and 20-27 (severe) ${ }^{28}$ we observed (no depression; $n=72,80 \%$ ), (mild; $n=9,10 \%$ ), (moderate; $n=5,5.5 \%)$, (moderately severe; $n=3,3.3 \%$ ), and (severe; $n=1,1.2 \%)$. Similarly using the same scoring convention for the GAD-7 Anxiety (no anxiety; $n=80,84.2 \%$ ), (mild; $n=9,9.5 \%$ ), (moderate; $n=2,2.1 \%$ ), 
(moderately severe; $n=3,3.1 \%$ ) and (severe; $n=1,1.1 \%$ ). We used the cut of score of $4 \geq$ on the distress thermometer ${ }^{23}$ ( $\left.n=14,14.2 \%\right)$ were at risk of experiencing clinically significant levels of distress.

\section{Barriers to accessing health care}

Overall most of the participants in the study did not perceive barriers to accessing supportive care in the UK and Australia. However, patients perceived barriers to accessing supportive care services due to a lack of information, see Table 4. Patients identified gaps in their experience of information provision in service delivery, with a focus on the consequences of ADT and how to self-manage their associated side-effects. Other patients highlighted a lack of understanding about how to navigate the complex care system to access services which they may have required. Patients also shared positive experiences of supportive care delivery in the UK and Australia which was related to having good access to specialist nurses.

\section{Discussion}

To our knowledge, this is the first bi-country study conducted to explore the unmet supportive care needs and barriers to engagement in support services for men living with locally advanced or metastatic prostate cancer receiving androgen deprivation therapy. The primary focus of this study was to gain more information about the experience of unmet supportive care in men affected by advanced prostate cancer. Interestingly, we did not observe any statistically significant differences in the reported domains of unmet needs between participants in the UK and Australia. These results are in keeping with existing studies that have persistently reported unmet supportive care needs in developed countries, such as Canada ${ }^{9}$, Australia ${ }^{10}$, and the UK ${ }^{8,12}$ for men affected by advanced prostate cancer. Thus indicating that key areas of supportive care domains remain suboptimal for some men. To date, most studies that have explored unmet needs of men affected by locally advanced or metastatic prostate cancer receiving ADT have been conducted within one state or country ${ }^{8-10}$ and therefore, our results add an important international clinical contribution. Regardless 
of the geographical location in which existing studies have be conducted, participants commonly report areas of unmet needs related to informational, psychological and sexual needs, this underscores that further global intervention studies are required to address these inherent gaps in care provision for men.

Generally, facilitating access is concerned with helping people to command appropriate healthcare resources to persevere or improve patient's health ${ }^{31}$. We considered the barriers of accessing support in the context of differing patient perspectives which included the patient's health needs, and material and cultural needs of a diverse group across two countries. Most men in this study did not reported any perceived barriers to accessing support services. However, of the men who did perceive barriers, these were related to a lack of information provision, particularly around treatment, self-management and patient navigation in the healthcare system. These findings are consistent with those published elsewhere ${ }^{12,32}$ in that men may require multimodal interventions and active encouragement to overcome barriers and access additional support for rehabilitation related to sexual and emotional issues.

A clinically important finding was that approximately twenty percent of the study sample were at risk of anxiety and depression. Our results report similar prevalence rates to those published in a metaanalysis on the prevalence rates on anxiety and depression among men affected by prostate cancer 33. Furthermore, around fifteen percent were at risk of experiencing significant levels of distress. This emphasises that despite routine clinical follow-up patients are not receiving the timely and tailored person-centred interventions required. Patient reported outcome measures (PROMs) were originally developed for research use, but as proactive clinicians have recognised the benefits of PROMs they have gained additional use in routine clinical practice ${ }^{34}$. Through the routine use of PROMs in clinical practice this may help clinicians to appropriately risk stratify patients who need tailored interventions. Currently, we do not have a universally agreed PROM for routine use in prostate cancer care. We would recommend that ideally the same PROM should be used in clinical practice and research trials 
to avoid the concurrent disconnect and when interpreting trial results and the associated difficulties in translating them into routine clinical practice.

A further clinically relevant finding was in relation to the time since diagnosis of men diagnosed with prostate cancer and the duration of ADT between the men in the UK and Australia. Despite this observed difference between both study groups we did not observe any statistically significant difference in anxiety, depression, distress or quality of life scores, with the exception for the urinary incontinence domain.

\section{Strengths/Limitations}

There were several limitations worthy of comment. The number of participants recruited into the study were lower than expected but due to ethical confinements, we were unable to explore recruitment bias with a range of clinical or demographic variables. However, this is one of the largest studies to date to explore elderly men's experience of unmet needs, and this was a strength. Approximately $40 \%$ of the participants were over 80 years of age, and noteworthy the oldest participant was 97 years old. The participants were biased in favour of Caucasian, married, Englishspeaking and retired men which limits the generalisability of this study. Further research is urgently needed to explore areas of unmet needs with different demographic groups, other than those represented in our study, including typically hard to reach groups, such as Aboriginal and Torres Strait islander patient populations.

This was a cross-sectional study that had good representation of patients who were diagnosed within one year to 30 years of receiving ADT, but these results only provided a snapshot of the experience of unmet needs at one given time point. Moreover, the recruitment pathways of the men who took part in this study may not be representative of those in other geographical areas in both respective countries. Further prospective longitudinal research is required to understand how needs change over time. Moreover, future studies should explore potential clinical and demographic variables that may 
predict domains of unmet needs to enable clinicians to identify those patients at higher risk. Relatedly, dyadic quantitative, qualitative studies and complex interventions could enhance our understanding of the relationship dynamics and manifestations of interrelated needs.

\section{Conclusion}

Men affected by advanced prostate cancer receiving ADT report unmet supportive care needs related to sexual, informational and psychological aspects of care. Mapping the trajectories of needs and identifying men at higher risk can significantly improve our ability to offer more timely and tailored interventions. Future research is needed to explore whether demographic and clinical factors may moderate or mediate the manifestation of needs for men affected by prostate cancer receiving ADT over time. Meanwhile, clinicians are encouraged to use these findings in their everyday clinical consultations with men to distinguish individual needs and priorities to ensure effective, safe and person-centred care. 


\section{References}

1. Bray F, Ferlay J, Soerjomataram I, Siegel RL, Torre LA, Jemal A. Global cancer statistics 2018: GLOBOCAN estimates of incidence and mortality worldwide for 36 cancers in 185 countries. CA: a cancer journal for clinicians. 2018;68(6):394-424.

2. European Association Urology. European Association of Urology Guidelines. 2018 Edition. Vol presented at the EAU Annual Congress Copenhagen 2018. Arnhem, The Netherlands: European Association of Urology Guidelines Office; 2018.

3. James ND, de Bono JS, Spears MR, et al. Abiraterone for Prostate Cancer Not Previously Treated with Hormone Therapy. N Engl J Med. 2017;377(4):338-351.

4. Fizazi K, Tran N, Fein L, et al. Abiraterone plus Prednisone in Metastatic, Castration-Sensitive Prostate Cancer. N Engl J Med. 2017;377(4):352-360.

5. McNamara MA, George DJ, Ramaswamy K, et al. Overall survival by race in chemotherapynaïve metastatic castration-resistant prostate cancer (mCRPC) patients treated with abiraterone acetate or enzalutamide. 2019;37(7):212-212.

6. Fizazi K, Tran N, Fein LE, et al. Final analysis of phase III LATITUDE study in patients (pts) with newly diagnosed high-risk metastatic castration-naïve prostate cancer (NDx-HR mCNPC) treated with abiraterone acetate + prednisone $(A A+P)$ added to androgen deprivation therapy (ADT). Journal of Clinical Oncology. 2019;37(7_suppl):141-141.

7. Davis I, Martin A, Stockler M, et al. Enzalutamide with Standard First-Line Therapy in Metastatic Prostate Cancer. The New England journal of medicine. 2019;381(2):121-131.

8. Paterson C, Kata SG, Nandwani G, Chaudhury DD, Nabi G. Unmet supportive care needs of men with locally advanced and metastatic prostate cancer on hormonal treatment: a mixed methods study. Cancer nursing. 2017;40(6):497-507.

9. Carter N, Bryant-Lukosius D, DiCenso A, Blythe J, Neville AJ. The supportive care needs of men with advanced prostate cancer. Oncology Nursing Forum. 2011;38(2).

10. Chambers SK, Hyde MK, Laurie K, et al. Experiences of Australian men diagnosed with advanced prostate cancer: a qualitative study. BMJ open. 2018;8(2):e019917.

11. Zajdlewicz L, Hyde MK, Lepore SJ, Gardiner RA, Chambers SK. Health-related quality of life after the diagnosis of locally advanced or advanced prostate cancer: a longitudinal study. Cancer nursing. 2017;40(5):412-419.

12. Primeau C, Paterson C, Nabi G. A Qualitative Study Exploring Models of Supportive Care in Men and Their Partners/Caregivers Affected by Metastatic Prostate Cancer. Oncology nursing forum. 2017;44(6):E241.

13. Jenkins V, Solis-Trapala I, Payne $\mathrm{H}$, et al. Treatment experiences, information needs, pain and quality of life in men with metastatic castrate-resistant prostate cancer: results from the EXTREQOL study. Clinical Oncology. 2019;31(2):99-107.

14. Khalaf DJ, Sunderland K, Eigl BJ, et al. Health-related Quality of Life for Abiraterone Plus Prednisone Versus Enzalutamide in Patients with Metastatic Castration-resistant Prostate Cancer: Results from a Phase II Randomized Trial. European Urology. 2019;75(6):940-947.

15. Paterson C, Robertson A, Smith A, Nabi G. Identifying the unmet supportive care needs of men living with and beyond prostate cancer: a systematic review. European Journal of Oncology Nursing. 2015;19(4):405-418.

16. Grant SJ, Hunter J, Seely D, Balneaves LG, Rossi E, Bao T. Integrative oncology: International perspectives. Integrative cancer therapies. 2019;18.

17. King A, Evans M, Moore T, et al. Prostate cancer and supportive care: a systematic review and qualitative synthesis of men's experiences and unmet needs. European journal of cancer care. 2015;24(5):618-634.

18. Paterson C, Nabi G. A model of consultation in prostate cancer care: evidence from a systematic review. Cancer nursing. 2017;40(4):276-288. 
19. Boyes A, Girgis A, Lecathelinais C. Brief assessment of adult cancer patients' perceived needs: development and validation of the 34-item Supportive Care Needs Survey (SCNSSF34). Journal of evaluation in clinical practice. 2009;15(4):602-606.

20. Schofield P, Gough K, Lotfi-Jam K, Aranda S. Validation of the Supportive Care Needs Survey-short form 34 with a simplified response format in men with prostate cancer. Psycho-Oncology. 2012;21(10):1107-1112.

21. Szymanski KM, Wei JT, Dunn RL, Sanda MG. Development and validation of an abbreviated version of the expanded prostate cancer index composite instrument for measuring healthrelated quality of life among prostate cancer survivors. Urology. 2010;76(5):1245-1250.

22. Godin G. The Godin-Shephard leisure-time physical activity questionnaire. The Health \& Fitness Journal of Canada. 2011;4(1):18-22.

23. Chambers SK, Zajdlewicz L, Youlden DR, Holland JC, Dunn J. The validity of the distress thermometer in prostate cancer populations. Psycho-Oncology. 2014;23(2):195-203.

24. Spitzer RL, Kroenke K, Williams JB, Löwe B. A brief measure for assessing generalized anxiety disorder: the GAD-7. Archives of internal medicine. 2006;166(10):1092-1097.

25. Segal DL. Diagnostic and Statistical Manual of Mental Disorders (DSM-IV-TR). The Corsini Encyclopedia of Psychology. 2010:1-3.

26. Löwe B, Decker O, Müller S, et al. Validation and standardization of the Generalized Anxiety Disorder Screener (GAD-7) in the general population. Medical care. 2008;46(3):266-274.

27. Andersen BL, DeRubeis RJ, Berman BS, et al. Screening, assessment, and care of anxiety and depressive symptoms in adults with cancer: an American Society of Clinical Oncology guideline adaptation. Journal of Clinical Oncology. 2014;32(15):1605.

28. Kroenke K, Strine TW, Spitzer RL, Williams JB, Berry JT, Mokdad AH. The PHQ-8 as a measure of current depression in the general population. Journal of affective disorders. 2009;114(13):163-173.

29. Burg MA, Zebrack B, Walsh $\mathrm{K}$, et al. Barriers to accessing quality health care for cancer patients: a survey of members of the association of oncology social work. Social work in health care. 2010;49(1):38-52.

30. Tabachnick B, Fidell L. Using Multivariate Statistics. New York: Harper \& Row, Publishers, Inc.; 1989.

31. Feldman-Stewart D, Tong C, Brundage M, Bender J, Robinson J. Prostate cancer patients' experience and preferences for acquiring information early in their care. Canadian Urological Association Journal. 2018;12(5):E219.

32. Hedden L, Pollock P, Stirling B, Goldenberg L, Higano C. Patterns and predictors of registration and participation at a supportive care program for prostate cancer survivors. Supportive Care in Cancer. 2019:1-11.

33. Watts $\mathrm{S}$, Leydon $\mathrm{G}$, Birch B, et al. Depression and anxiety in prostate cancer: a systematic review and meta-analysis of prevalence rates. BMJ open. 2014;4(3):e003901.

34. Hutchings HA, Alrubaiy L. Patient-reported outcome measures in routine clinical care: the PROMise of a better future? 2017;62(8):1841-1843. 
Table 1. Distribution of clinical and demographic characteristics.

Characteristics N\%

\section{Country response}

United Kingdom

41

61

Australia

Age

61-70 years

20

38

35

81-90 years

90-100 years

Marital status

Single/never married

Divorced or separated

Married

Living with partner

Widowed

Sexual orientation

Heterosexual

Gay

Bisexual

Other

Missing data

Race

White

Indigenous

Asian

Other

Missing data

Highest qualification

School education only

TAFE qualification

Bachelor degree

Honours degree

Postgraduate certificate

Postgraduate diploma

Master's degree

Master's degree by research

Doctorate

Other

Missing data
40.2

59.8

19.6

37.3

34.3

8.8

2.0

3.9

76.5

2.9

14.7

92.2

0

1.0

2.9

3.9

86.3

1.0

2.9

4.9

4.9

43.1

15.7

10.8

2.0

2.0

2.0

3.9

1.0

3.9

14.7

1.0 
Private health insurance

Yes

No

Missing data

Employment

Working full-time

Working part-time

Unemployed

Retired

Missing

Time since diagnosis

0-1 years

6.9

2-5 years

6-10 years

11-20 years

21-30 years

Missing data

Duration of ADT*

$<1$ year

1-2 years

3-5 years

6-10 years

11-15 years

Continuous ADT

Yes

No

Missing

Abbreviation: ADT, androgen deprivation therapy. 
Table 2. Distributions of unmet supportive care needs (SCNS34).

\begin{tabular}{|c|c|c|c|c|c|}
\hline $\begin{array}{l}\text { Unmet Need* In the } \\
\text { last month, what was } \\
\text { your level of need for } \\
\text { help with: }\end{array}$ & $\begin{array}{c}\text { This was } \\
\text { not a } \\
\text { problem } \\
\text { for me as a } \\
\text { result of } \\
\text { cancer } \mathbf{N} \\
(\%)\end{array}$ & $\begin{array}{c}\text { I did need } \\
\text { help with } \\
\text { this, but my } \\
\text { need for } \\
\text { help was } \\
\text { satisfied at } \\
\text { the time } N \\
(\%)\end{array}$ & $\begin{array}{c}\text { Low unmet } \\
\text { need. I had } \\
\text { little need } \\
\text { for } \\
\text { additional } \\
\text { help N (\%) }\end{array}$ & $\begin{array}{c}\text { Moderate } \\
\text { unmet need. } \\
\text { I had some } \\
\text { need for } \\
\text { additional } \\
\text { help N (\%) }\end{array}$ & $\begin{array}{c}\text { High unmet } \\
\text { need. I had } \\
\text { strong need } \\
\text { for } \\
\text { additional } \\
\text { help N (\%) }\end{array}$ \\
\hline Pain & $77(77)$ & $8(8)$ & $7(7)$ & $6(6)$ & $2(2)$ \\
\hline $\begin{array}{l}\text { Lack of } \\
\text { energy/tiredness }\end{array}$ & $43(43.4)$ & $25(25.3)$ & $10(10.1)$ & $15(15.2)$ & $6(6.1)$ \\
\hline $\begin{array}{l}\text { Feeling unwell a lot } \\
\text { of the time }\end{array}$ & $73(74.5)$ & $9(9.2)$ & $11(11.2)$ & $3(3.1)$ & $2(2)$ \\
\hline $\begin{array}{l}\text { Work around the } \\
\text { home }\end{array}$ & $62(63.9)$ & $16(16.5)$ & $14(14.4)$ & $3(3.1)$ & $2(1.9)$ \\
\hline $\begin{array}{l}\text { Not being able to do } \\
\text { the things that you } \\
\text { used to do }\end{array}$ & $41(41.8)$ & $23(23.5)$ & $19(19.4)$ & $9(9.2)$ & $6(6.1)$ \\
\hline Anxiety & $61(61.6)$ & $16(16.2)$ & $18(17.5)$ & $3(2.9)$ & $1(1)$ \\
\hline $\begin{array}{l}\text { Feeling down or } \\
\text { depressed }\end{array}$ & $64(65.3)$ & $14(14.3)$ & $13(13.3)$ & $5(5.1)$ & $2(2.0)$ \\
\hline Feelings of sadness & $64(64.6)$ & $15(15.2)$ & $15(15.2)$ & $4(4.0)$ & $1(1.0)$ \\
\hline $\begin{array}{l}\text { Fear about the } \\
\text { cancer spreading }\end{array}$ & $36(36.4)$ & $35(35.4)$ & $19(19.2)$ & $7(7.0)$ & $2(2.0)$ \\
\hline $\begin{array}{l}\text { Worry that the } \\
\text { results of treatment } \\
\text { are beyond your } \\
\text { control }\end{array}$ & $53(53.5)$ & $21(21.2)$ & $18(18.2)$ & $5(5.1)$ & $2(2.0)$ \\
\hline $\begin{array}{l}\text { Uncertainty about } \\
\text { the future }\end{array}$ & $46(46.5)$ & $23(23.2)$ & $21(21.2)$ & $6(6.1)$ & $3(3.0)$ \\
\hline $\begin{array}{l}\text { Learning to feel in } \\
\text { control of your } \\
\text { situation }\end{array}$ & $53(53.5)$ & $22(22.2)$ & $20(20.3)$ & $2(2.0)$ & $2(2.0)$ \\
\hline $\begin{array}{l}\text { Keeping a positive } \\
\text { outlook }\end{array}$ & $59(60.2)$ & $24(24.5)$ & $11(11.2)$ & $2(2.0)$ & $2(2.0)$ \\
\hline $\begin{array}{l}\text { Feelings about death } \\
\text { and dying }\end{array}$ & $59(59.6)$ & $21(21.2)$ & $14(14.1)$ & $4(4.0)$ & $1(1.0)$ \\
\hline $\begin{array}{l}\text { Changes in sexual } \\
\text { feelings }\end{array}$ & $61(62.2)$ & $16(16.3)$ & $10(10.2)$ & $7(7.1)$ & $4(4.1)$ \\
\hline $\begin{array}{l}\text { Changes in sexual } \\
\text { relationships }\end{array}$ & $64(65.3)$ & $15(15.3)$ & $8(8.2)$ & $6(6.1)$ & $5(5.1)$ \\
\hline $\begin{array}{l}\text { Concerns about the } \\
\text { worries of those close } \\
\text { to you }\end{array}$ & $37(37.0)$ & $30(30.0)$ & $19(19.0)$ & $8(8.0)$ & $6(6.0)$ \\
\hline
\end{tabular}




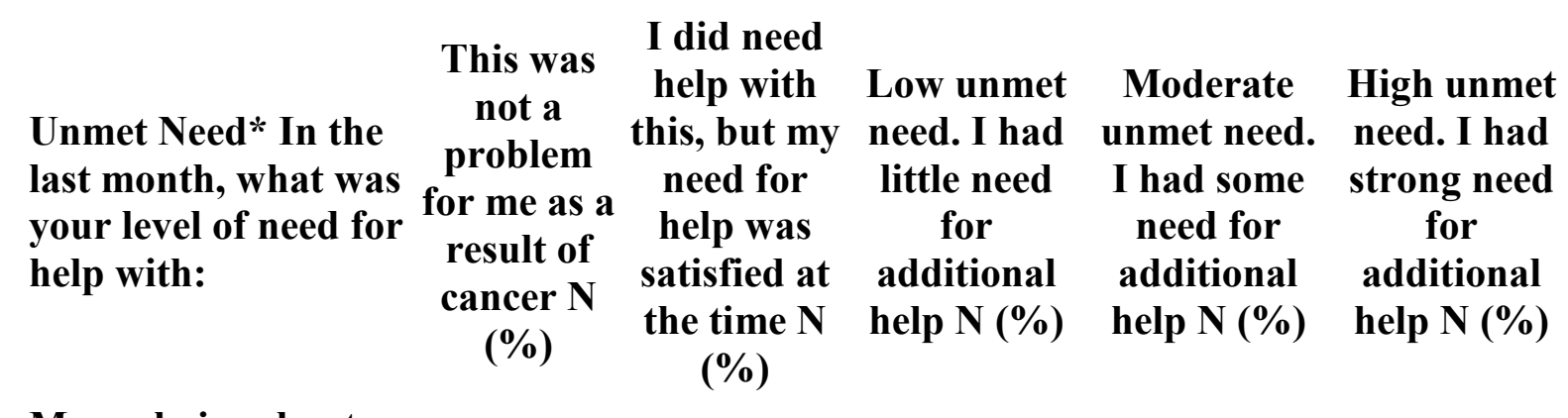

More choice about

which cancer

$65(65.7) \quad 22(22.2) \quad 8(8.1) \quad 3(3.0) \quad 1(1.0)$

specialist you see

More choice about

which hospital you

attend

$63(64.9) \quad 25(25.8) \quad 5(5.2) \quad 1(1.0)$

$3(3.1)$

Reassurance by

medical staff that the

way you feel is

$59(59.6) \quad 31(31.3) \quad 8(8.1) \quad 1(1.0) \quad 0(0)$

normal

Hospital staff

attending promptly

to your physical

$64(65.3) \quad 28(28.6) \quad 5(5.1) \quad 1(1.0)$

$0(0)$

needs

Hospital staff

acknowledging, and

showing sensitivity

to, your feelings and

$66(66.7) \quad 28(28.3) \quad 4(4.0) \quad 2(1.0) \quad 0(0)$

emotional needs

Being given written

information about

the important

$70(70.7) \quad 19(19.2) \quad 5(5.1)$

$4(4.0)$

$1(1.0)$

aspects of your care

Being given

information (written

diagrams, drawings)

about managing your

$67(67.7) \quad 23(23.2) \quad 3(3.0)$

$5(5.1)$

$1(1.0)$

illness and side

effects at home

Being given

explanations for

those tests for which

you would like

explanations

Being adequately

informed about the

benefits and side

effects of treatment

$51(52.0) \quad 33(33.7) \quad 8(8.2)$

$4(4.1)$

$2(2.0)$

before you choose to

have them 


\begin{tabular}{|c|c|c|c|c|c|}
\hline $\begin{array}{l}\text { Unmet Need* In the } \\
\text { last month, what was } \\
\text { your level of need for } \\
\text { help with: }\end{array}$ & $\begin{array}{l}\text { This was } \\
\text { not a } \\
\text { problem } \\
\text { for me as a } \\
\text { result of } \\
\text { cancer } \mathrm{N} \\
(\%)\end{array}$ & $\begin{array}{c}\text { I did need } \\
\text { help with } \\
\text { this, but my } \\
\text { need for } \\
\text { help was } \\
\text { satisfied at } \\
\text { the time } N \\
(\%)\end{array}$ & $\begin{array}{c}\text { Low unmet } \\
\text { need. I had } \\
\text { little need } \\
\text { for } \\
\text { additional } \\
\text { help N (\%) }\end{array}$ & $\begin{array}{c}\text { Moderate } \\
\text { unmet need. } \\
\text { I had some } \\
\text { need for } \\
\text { additional } \\
\text { help N (\%) }\end{array}$ & $\begin{array}{r}\text { High un } \\
\text { need. I } \\
\text { strong I } \\
\text { for } \\
\text { additio } \\
\text { help } \mathbf{N}\end{array}$ \\
\hline $\begin{array}{l}\text { Being informed } \\
\text { about test results as } \\
\text { soon as feasible }\end{array}$ & $43(43.9)$ & $41(41.8)$ & $8(8.2)$ & $2(2.0)$ & $4(4.1)$ \\
\hline $\begin{array}{l}\text { Being informed } \\
\text { about cancer that is } \\
\text { under control or } \\
\text { diminishing }\end{array}$ & $47(48)$ & $39(39.8)$ & $3(3.1)$ & $6(6.1)$ & $3(3.1)$ \\
\hline $\begin{array}{l}\text { Being informed } \\
\text { about the things that } \\
\text { you can do to get well }\end{array}$ & $41(42.3)$ & $38(39.2)$ & $8(8.2)$ & $5(5.2)$ & $5(5.2)$ \\
\hline $\begin{array}{l}\text { Having access to } \\
\text { professional } \\
\text { counselling }\end{array}$ & $56(57.1)$ & $29(29.6)$ & $6(6.1)$ & $3(3.1)$ & $4(4.1)$ \\
\hline $\begin{array}{l}\text { Being given } \\
\text { information about } \\
\text { sexual relationships }\end{array}$ & $67(68.4)$ & $18(18.4)$ & $7(7.1)$ & $3(3.1)$ & $3(3.1)$ \\
\hline $\begin{array}{l}\text { Being treated like a } \\
\text { person not just } \\
\text { another case }\end{array}$ & $54(55.7)$ & $35(36.1)$ & $5(5.2)$ & $0(0)$ & $3(3.1)$ \\
\hline $\begin{array}{l}\text { Being treated in a } \\
\text { hospital or clinic that } \\
\text { is as physically } \\
\text { pleasant as possible }\end{array}$ & $49(50.0)$ & $43(43.9)$ & $3(3.1)$ & $0(0)$ & $3(3.1)$ \\
\hline $\begin{array}{l}\text { Having one member } \\
\text { of hospital staff with } \\
\text { whom you can talk to }\end{array}$ & $52(53.1)$ & $35(35.7)$ & $7(7.1)$ & $0(0)$ & $4(4.1)$ \\
\hline \multicolumn{6}{|c|}{ Distributions of Unmet Supportive Care Needs (prostate cancer supplement) } \\
\hline Urinary incontinence & $67(68.4)$ & $17(17.3)$ & $11(11.2)$ & $1(1.0)$ & $2(2.0)$ \\
\hline $\begin{array}{l}\text { Difficulties in passing } \\
\text { urine }\end{array}$ & $79(79.8)$ & $15(15.2)$ & $3(3.0)$ & $1(1.0)$ & $1(1.0)$ \\
\hline Hot flushes & $57(57.0)$ & $23(23.0)$ & $8(8.0)$ & $10(10.0)$ & $2(2.0)$ \\
\hline $\begin{array}{l}\text { Feeling as if you are } \\
\text { going through a } \\
\text { change of life like } \\
\text { women do }\end{array}$ & $65(65.7)$ & $15(15.2)$ & $10(10.1)$ & $8(8.1)$ & $1(1.0)$ \\
\hline $\begin{array}{l}\text { Feeling like you've } \\
\text { lost part of your } \\
\text { manhood }\end{array}$ & $55(55.6)$ & $23(23.2)$ & $5(5.1)$ & $8(8.1)$ & $8(8.1)$ \\
\hline
\end{tabular}




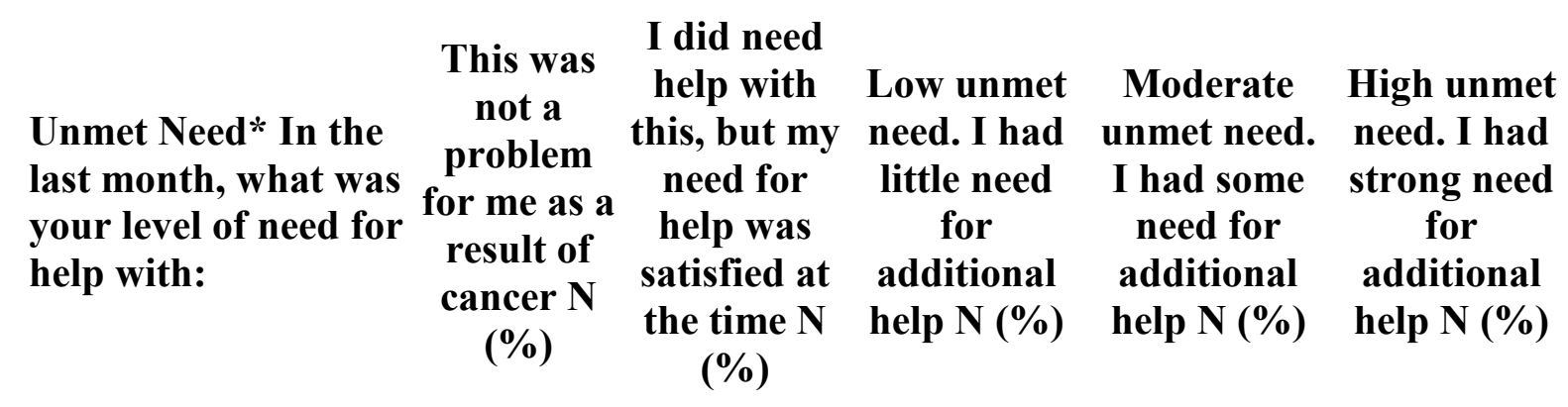

Feeling that what

$\begin{array}{lllll}\text { you say is not taken } 70(70.0) & 21(21.0) & 5(5.0) & 4(4.0) & 0(0)\end{array}$

seriously by others

Feeling like you have

$\begin{array}{lllll}\text { lost the ability to be } 71(71.7) & 21(21.2) & 6(6.1) & 1(1.0) & 0(0)\end{array}$

aggressive

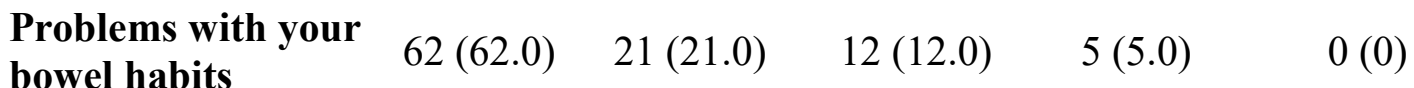

Table 3. Distribution of scores between study participants in Australia and UK on standardised questionnaires.

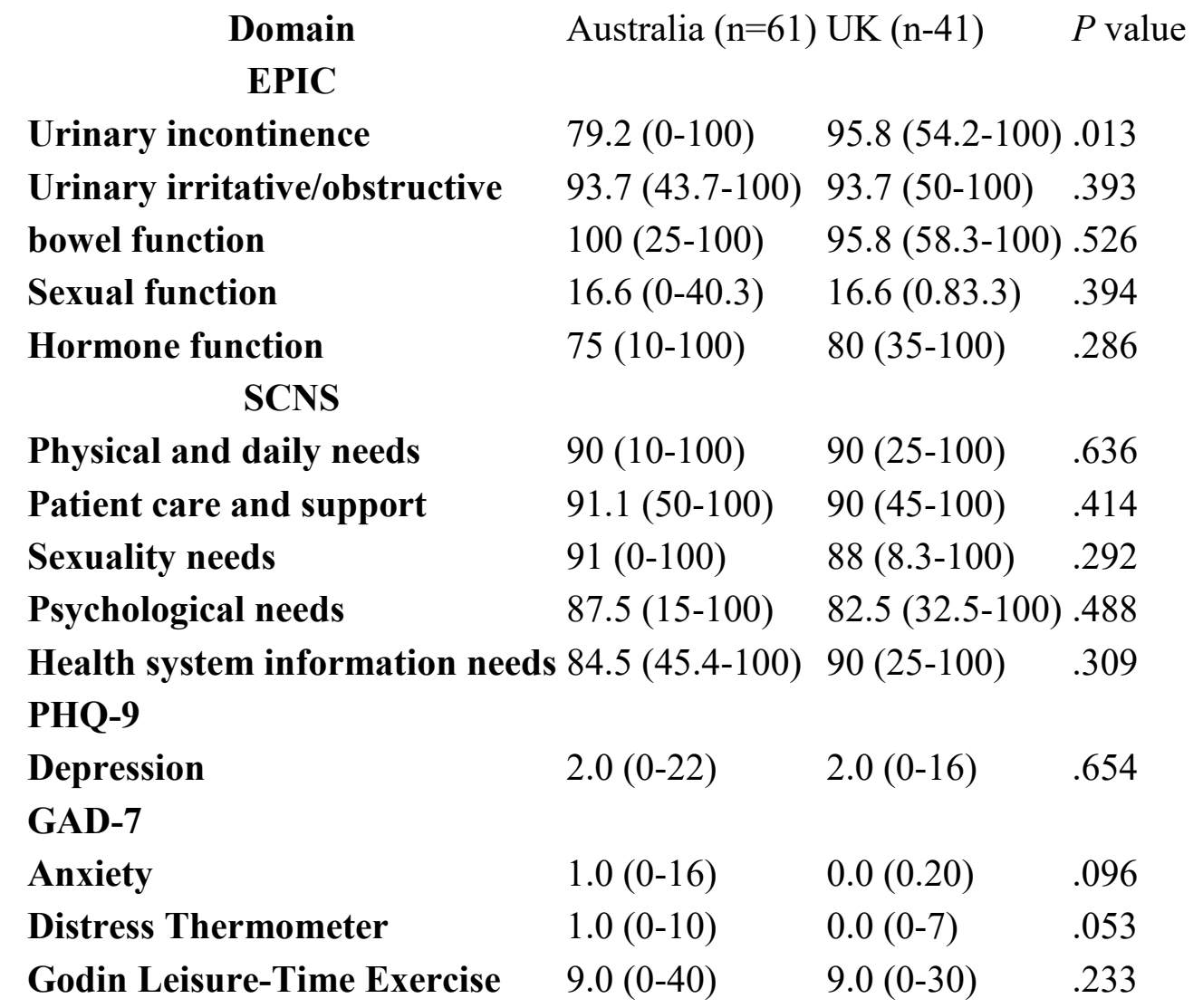


Table 4. Perceived barriers to access to supportive care services.

Inadequate health insurance

Lack of co-ordination of care among service provides

UK Australia

$(n=41) \quad(n=61)$

Too much time waiting for an appointment

15

22

Inability to pay for treatment related expenses

$4 \quad 1$

Transportation problems

Lack of child or elderly care

12

Language barriers

$1 \quad 1$

21

Cultural barrier

$0 \quad 1$

Anxiety

Depression

Worries that work wages will be lost

Lack of information

$0 \quad 1$

$0 \quad 1$

$1 \quad 1$

$1 \quad 1$

15

Ignoring physical pain or symptoms

Lack of information about where to find appropriate care

$1 \quad 1$

Other health problems

$0 \quad 3$

$1 \quad 1$

Too busy with other commitments

$0 \quad 2$

Reluctant to participate in health care decisions

32

Patients open qualitative comments

Facilitators and positive experiences

Australia

Each individual, in the services I've used, has shown nothing but excellence in their efforts on my behalf. I congratulate them and can't UK thank them enough.

All therapies and advice have been of very great help to me.

UK

I have been to Maggie's (Cancer Care Centre) and found the info I received to be very helpful. Plus the fact the nurse who dealt with me was extremely proficient.

EPC (Epworth Prostate Centre) provides a wonderful forum for discussion of all issues related to $A D T$.

My urologist, nurse and GP have all been excellent. I am in contact with the nurses if I have any queries and receive immediate replies.

UK

Coping strategies

No barriers sought. I have conquered my life and activities as I have been in the past and am not aware of any effects of hormone therapy apart from inability to produce an erection fully or at all.

The first 6 months were difficult coming to terms with the illness, etc. A TURP operation in the late 2014 made a huge difference and since then I have tried to continue my normal life as much as possible, I take lots of exercise and remain positive. Should I consider I need additional help with any aspect of my illness I will not hesitate to ask. 
UK Australia

$(n=41) \quad(n=61)$

I have an appointment with sexual therapy this month. I am very grateful for the quality of care and attention I have experienced.

Barriers to supportive care

UK

Lack of information

Australia

I am surprised that having finished taking my tablets for 28 days early July I have no further contact with medical services until September, but I figure they know what they are doing.

A simple information sheet with services and access points provided at time of treatment commenced (or before) would be highly beneficial.

Information needed about ALL side effects of ADT: impact on incontinence \& nervous system was lacking

Australia

Australia

Australia

Like to know what hormone therapy is?

I discussed all issues with my GP he felt further referrals unnecessary

Australia

Low energy \& tiredness need to be addressed Lack of knowledge of available services I gave up driving on my 88th birthday and reaching the Hospital is difficult but not excessive. I fractured my right femur in a cycling accident late last year and coupled with vision problems I may require transport help in the future. I would appreciate a monthly visit by a district nurse, but they consider me too mobile to benefit from this service.

No supportive services have been offered. Do not know what is available. Feel isolated. What services?

Abbreviations: ADT, androgen deprivation therapy; GP, general practitioner; TURP, transurethral resection of the prostate. 